\title{
CASE REPORT \\ COMBINED SEVERE AORTIC AND PULMONARY VALVULAR STENOSIS IN A CHILD AND ITS MANAGEMENT: A CASE REPORT
}

\author{
Usman Rashid $^{1}$, Rashid Nawaz ${ }^{2}$, Zile Fatima' ${ }^{1}$, Shaifa Ashraf ${ }^{1}$ \\ ${ }^{1}$ Children Hospital Faisalabad, Punjab, Pakistan, ${ }^{2}$ DHQ hospital Faisalabad, Punjab, Pakistan
}

\begin{abstract}
Combined congenital aortic and pulmonary valvular stenosis is a rare congenital heart defect. Prevalence of severe combined valvular stenosis of aortic and pulmonary valve accounts about $0.01 \%$ and also has association with many syndromes. This combination presents unusual diagnostic as well as management problems. Apart from a few case reports, there is little in the literature on the combined stenosis of both semilunar valves and its management. We present this rare combination in a 9 year old boy which was promptly managed with the balloon valvoplasty without any complications in the same setting under local anesthesia with sedation. Keywords: Valvular aortic stenosis, Valvular pulmonary stenosis, Semilunar valves, Balloon valvoplasty

Citation: Rashid U, Nawaz R, Fatima Z, Ashraf S. Combined Severe Aortic and Pulmonary Valvular Stenosis in a
Child and its Management: A Case Report. Pak Heart J. 2021;54(04):377-379. DOI:
https://doi.org/10.47144/phj.v54i4.2131
\end{abstract}

\section{INTRODUCTION}

Congenital aortic and pulmonary valvular stenosis is not an uncommon defect in pediatric population. Prevalence of isolated pulmonary stenosis in pediatric population in local regional data is $2.6 \%^{1}$ and around $8-10 \%{ }^{2}$ in the western world literature. The prevalence for isolated aortic stenosis is $1.4 \% .^{1}$ The combined stenosis of both valves in the same patient is a rare entity. The combined valvular stenosis is usually associated with other congenital heart defects like Atrial Septal Defect, Ventricular Septal Defect and Patent Ductus Arteriosus. Occasionally, it may have syndromic association like Noonan and William syndrome. But isolated severe left and right outflow tract obstruction is very rare in literature and only 16 cases have been reported. ${ }^{3-10}$ The first report was published in 1957 by Horlick ${ }^{3}$ and treated with surgical option. Later on, another case was reported by Chandrashekhar $\mathrm{Y}$ et al and managed by balloon valvoplasty instead of surgery. ${ }^{6}$ The increased importance of combined aortic stenosis (AS) and pulmonary stenosis (PS), in addition to its rarity, is the fact that delayed diagnosis and management may have catastrophic consequences. The procedure was done under local anesthesia with sedation which also has its own implications in developing countries where pediatric anesthetist is not readily available.

\section{CASE REPORT}

Nine years old boy with normal growth and developmental parameters, presented with history of mild distress on exertion (NYHA class I), and parental concern about chest deformity and hyper dynamic precordium. He was product of consanguineous marriage. On physical examination, the weight was on $50^{\text {th }}$ centile and height was on $25^{\text {th }}$ centile. He was pink in room air with pulse of 94 beats/min, regular and synchronous and blood pressure (BP) of 108/70 $\mathrm{mmHg}$. Cardiac examination revealed a precordial bulge, pulsatile and hyper dynamic precordium with apex beat in $6^{\text {th }}$ intercostal space which was heaving in character (well sustained heave). Left parasternal heave was also palpable. Systolic thrill was palpable in both left and right $2^{\text {nd }}$ intercostal and supra sternal notch. On auscultation, there was a grade IV ejection systolic murmur in left $2^{\text {nd }}$ intercostal space with an additional grade IV ejection systolic murmur in right $2^{\text {nd }}$ intercostal space with radiation to neck.

Electrocardiogram (ECG) revealed sinus tachycardia with normal left axis deviation. There were also features of bi- ventricular hypertrophy with deep $\mathrm{S}$ waves in lead V1 and V6 but left ventricular hypertrophy was more marked. Chest X Ray revealed cardiomegaly with predominant left ventricle (LV) as apex was formed by LV along with no uplifting of apex. But right atrium (RA) and pulmonary artery (PA) shadow was also enlarged suggesting severe pulmonary stenosis as well. Two-dimensional echocardiography showed a thickened, dysplastic, bicuspid aortic valve with maximum instantaneous gradient of $96 \mathrm{mmHg}$ and mean gradient of $78 \mathrm{mmHg}$ with peak velocity of $4.9 \mathrm{~m} / \mathrm{s}$ across the valve. The aortic annulus was $12.3 \mathrm{~mm}$ and there was marked hypertrophy of left ventricle. Additionally, there was doming pulmonary valve with maximum instantaneous gradient of $121 \mathrm{mmHg}$ and mean gradient was $97 \mathrm{mmHg}$ with peak velocity of $5.5 \mathrm{~m} / \mathrm{s}$ across the valve. On M-mode, there is normal systolic $\mathrm{LV}$ function with ejection fraction (EF) of $69 \%$ and tricuspid annular plane systolic excursion (TAPSE) of $18 \mathrm{~mm}$. The pulmonary valve annulus measured $16.1 \mathrm{~mm}$. 
The patient was taken to cardiac catheterization lab where dilatation of both aortic and pulmonary valves was done with balloon in the same setting. The procedure was performed under local anesthesia with sedation. The catheterization revealed a thickened aortic valve with severe aortic stenosis and trace aortic regurgitation (AR) and gradient across the aortic valve was $153 \mathrm{mmHg}$ with peak LV systolic pressure of 300 $\mathrm{mmHg}$ (Mean $122 \mathrm{mmHg}$ ). The aortic annulus was measured to be $12.1 \mathrm{~mm}$ on fluoroscopy. The aortic valve was crossed and dilated with a 12x3 mm Osypka balloon (VACS II) under cardiac pacing at $210 \mathrm{bpm}$ (Figure 1). Post balloon dilation, the gradient across the aortic valve dropped to $50 \mathrm{mmHg}$ with mild AR and peak LV pressure of $155 \mathrm{mmHg}$ (Mean $70 \mathrm{mmHg}$ ).
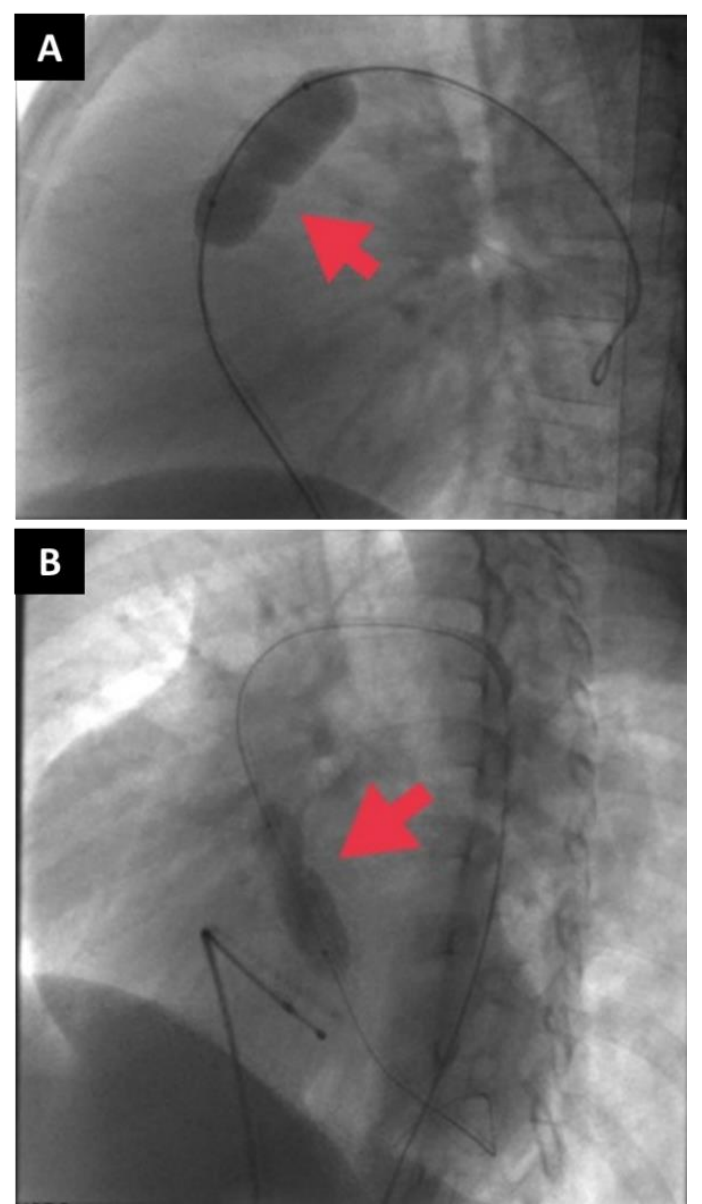

Figure 1: Pulmonary (A) and Aortic (B) balloon valvoplasty by using Osypka balloon (VACS II)

After aortic balloon valvoplasty, balloon dilatation of pulmonary valve was done. Gradient across the pulmonary valve was $96 \mathrm{mmHg}$ with mild pulmonary regurgitation. There was also marked post stenotic dilatation of pulmonary artery. The pulmonary valve annulus measured to be $14.1 \mathrm{~mm}$ and pulmonary balloon dilatation was done with $18 \times 3 \mathrm{~mm}$ Osypka balloon (VACS II) (Figure 1). The gradient across pulmonary valve reduced to $35 \mathrm{mmHg}$ after dilatation. No complication was observed during procedure and post procedure $2 \mathrm{D}$ echocardiography revealed aortic valve maximum instantaneous gradient of $4 \mathrm{mmHg}$ and pulmonary valve gradient of $49 \mathrm{mmHg}$ (Table 1).

Table 1: Pressure pre and post balloon pulmonary and aortic valvoplasty

\begin{tabular}{|l|c|c|}
\hline \multirow{2}{*}{ Site } & $\begin{array}{c}\text { Pre-Balloon } \\
\text { Valvoplasty }\end{array}$ & $\begin{array}{c}\text { Post-Balloon } \\
\text { valvoplasty }\end{array}$ \\
\cline { 2 - 3 } & (Peak, Mean mmHg) & (Peak, Mean mmHg) \\
\hline RV & $181(89)$ & $112(68)$ \\
\hline LPA & $85(41)$ & $77(44)$ \\
\hline LV & $300(122)$ & $155(70)$ \\
\hline AO & $147(129)$ & $105(72)$ \\
\hline
\end{tabular}

$\mathrm{RV}=$ right ventricular, LPA=left pulmonary arteries, $\mathrm{LV}=$ left ventricular, $\mathrm{AO}=$ aorta

The patient was discharged next day with stable vitals and no complication. The approval from institutional review board was taken for the publication of the case report.

\section{DISCUSSION}

Combined aortic and pulmonary valvular stenosis is a rare entity. Sometimes, this lesion is associated with either sub valvular or supra valvular stenosis which at times is difficult to deal with cardiac catheterization. Either alone or in combination, these lesions may have syndromic association like Noonan and William syndrome. Supra-valvular aortic stenosis and peripheral branch PA stenosis was a common feature in William syndrome. The prevalence of this rare combination is $0.01 \%$ of all congenital heart diseases. ${ }^{7}$ Literatures has shown the rarity of this combination and there are only 16 case reports of combined aortic and pulmonary stenosis till date. ${ }^{3-10}$ This number is even smaller in pediatric population and the children who were dealt with balloon valvoplasty. The first case report had been published by Horlick et al. in $1957^{3}$ and was managed by surgical correction. The first case report with successful balloon valvoplsty in adult was published by Chandrashekhar Y et al. ${ }^{6}$ in 1994 and in a neonate by da Cruz E et al. ${ }^{9}$ in 2007.

The age of presentation in all 17 cases (including one of ours) ranged from neonate to 55y. Like our case, there is slight male predominance in all the case reports with male: female ratio of 1.5:1. Majority of patients got attention due to hyper-dynamic precordium and a cardiac murmur. Some cases were suspected by dyspnea and fatigue and picked up clinically after detailed precordial examination. In our case, the left ventricle impulse, well sustained heaving apex beat and lateral displacement of apex revealed the predominant LV. But in some cases, RV component was more prominent. Just like in our case, majority of children in case reports ${ }^{7}$ had systolic thrill at both 
pulmonary and aortic areas. In our case, ECG showed biventricular hypertrophy with predominance of LV. But some case reports ${ }^{9}$ showed P-Pulmonale and prominent tall $\mathrm{R}$ wave in lead $\mathrm{V} 1$. These findings are relative and depends upon the severity of predominant lesion. Cardiomegaly on chest $\mathrm{X}$ ray was a universal finding in all the reported cases but with variability of ventricular predominance. The majority ${ }^{7-9}$ had right ventricle predominance but our case had left ventricle predominance.

The combined balloon aortic and pulmonary valvoplasty had been the procedure of choice since it had been successfully performed first in an adult patient $^{6}$ and then in a neonate. ${ }^{9}$ Morbidity and mortality can occur in any catheterization procedure and same is the case with combined valvoplasty. Usually arrhythmia is a common adverse event which happens when the wire is parked in the LV and bradycardia occurs during balloon dilatation ${ }^{7}$ particularly in children who are already hemodynamically compromised. Mild residual stenotic lesion is left in some patients just like in our case because of thickened dysplastic valve and high initial gradient across the valve.

There is always a query in combined stenotic lesions regarding management decision that which valve should be repaired first as the procedure has to be performed in the same setting. In our case, we opened the aortic valve first followed by pulmonary valve with a reason that left sided obstruction should be relieved first before the right sided obstruction. It is supported by the fact that opening the pulmonary valve first and relieving the right side obstruction in presence of left sided obstruction may lead to increased preload on LV. This may result in fatal pulmonary edema leading to pulmonary hemorrhage which is a well-documented complication of pulmonary valvoplasty and this complication will be more obvious in presence of compromised LV. ${ }^{11}$ This was the case in all the reported literature of combined balloon valvoplasty except a report published by Chandrashekhar $\mathrm{Y}$ et al. ${ }^{6}$ where they opened the pulmonary valve first to look the hemodynamic effect of relieving right sided obstruction on the left.

Although balloon aortic and pulmonary valvoplasty is a standard of care these days but the objective of the case report in addition to its rarity, is to help in decision making that which valve to be opened first and which type of anesthesia can be used in developing countries where public sector hospitals are handicapped in many ways. The use of local anesthesia with sedation demands a high degree of monitoring during the procedure particularly while pacing at a high rate and also post procedure good ICU care is mandatory.

In conclusion, combined aortic and pulmonary valvular stenosis is a rare disease and simultaneous correction of both valves by balloon valvoplasty is a successful and safe option to deal with these stenotic lesions under the same setting by local anesthesia and strict monitoring. Early recognition, timely correction and age of the child depict the success of the procedure.

\section{AUTHORS' CONTRIBUTION}

UR: Concept and design, data acquisition, interpretation, drafting, final approval, and agree to be accountable for all aspects of the work. RN, ZF, SA: Data acquisition, interpretation, drafting, final approval and agree to be accountable for all aspects of the work.

Conflict of interest: Authors declared no conflict of interest.

\section{REFERENCES}

1. Rashid U, Kazmi U, Saher T, Najam S, Sadiq M. Pattren of pediatric heart diseases in a tertiary care hospital in Pakistan. Pak Pediatr J. 2016;40(2):117-22.

2. Moss, Adams. Heart diseases in infants, children and adolescents including fetus and young adult. 10th ed., p. 835. Lippincott Williams \& Wilkins; 2018

3. Hoffman JI, Christianson R. Congenital heart disease in a cohort of 19,502 births with long-term follow-up. Am J Cardiol. 1978;42(4):641-7.

4. Kelly DT. Congenital stenosis of pulmonary and aortic valves. Am J Cardiol. 1965;16(5):750-3.

5. Fontes VF, Esteves CA, Silva MV, Pimentel Filho WA, Souza JE. Dupla valvoplastia com cateter-balão aórtico e pulmonar. Relato de caso [Double valvuloplasty with aortic and pulmonary balloon catheter. A case report]. Arq Bras Cardiol. 1987;48(2):105-7.

6. Chandrashekhar Y, Sen S, Bidwai PS, Khattri HN. Syndrome of combined aortic and pulmonary valve stenosis: successful treatment with balloon dilatation. Am Heart J. 1994;127(6):16313

7. Layangool T, Promphan W, Kirawittaya T, Sangtawesin C, Makarapong M .Combined aortic and pulmonic valvular stenosis: report of 2 cases. J Med Assoc Thai. 2011;94(3):S217-21

8. Shemin RJ, Kent KM, Roberts WC. Syndrome of valvular pulmonary stenosis and valvular aortic stenosis with atrial septal defect. Br Heart J. 1979; 42:442-6.

9. da Cruz E, Billieux MH, Beghetti M. A neonate with isolated combined aortic and pulmonary valvar stenosis. Int J Cardiol. 2007;116(1)

10. Gupta A, Hafeez I, Aslam K, Lone A, Alai MS, Iqbal K. Combined severe valvular aortic and valvular pulmonary stenosis and its management - A case report and literature review. J Saudi Heart Assoc. 2014;26(2):101-4.

11. Ostovan MA, Kamali M, Zolghadrasli A. A Case of Fatal Acute Lung Injury after Balloon Valvuloplasty of Pulmonary Stenosis: Case Report and Review of Literature. J Cardiovasc Thorac Res. 2015;7(2):78-80

\section{Address for Correspondence:}

Dr. Usman Rashid, Department of Pediatric cardiology, Children hospital Faisalabad, Punjab, Pakistan.

Email: drhero238@gmail.com 